\title{
Mindfulness as a Weight Loss Treatment for Veterans
}

\author{
Michael V. Stanton ${ }^{1,2 *}$, Justin Matsuura ${ }^{3}$, Jennifer Kaci Fairchild², Jessica A. Lohnberg ${ }^{2}$ \\ and Peter J. Bayley ${ }^{1,2}$
}

${ }^{1}$ Stanford University, Stanford, CA, USA, ${ }^{2}$ Veterans Affairs Palo Alto Health Care System, Palo Alto, CA, USA, ${ }^{3}$ US Army Health Clinic Schofield Barracks Brain Injury Clinic, Schofield Barracks, HI, USA

Despite substantial evidence for their effectiveness in treating disordered eating and obesity, mindfulness-based treatments have not been broadly implemented among Veterans. A number of reviews have reported mindfulness to be beneficial in promoting healthy eating behaviors and weight loss among non-Veteran samples. We discuss this approach in the context of the Veterans Affairs system, the largest integrated healthcare provider in the U.S. and in the context of Veterans, among whom obesity is at epidemic proportions. In this article, we discuss what is known about treating obesity using a

OPEN ACCESS

Edited by: Kelly Costello Allison,

Perelman School of Medicine, USA

Reviewed by:

Ashley A. Martin, University of Southern California, USA Lauren Bradley, Rush University Medical Center, USA

${ }^{*}$ Correspondence: Michael V. Stanton drmichaelstanton@gmail.com

Specialty section: This article was submitted to Eating Behavior,

a section of the journal Frontiers in Nutrition

Received: 27 April 2016 Accepted: 29 July 2016 Published: 15 August 2016

Citation:

Stanton MV, Matsuura J, Fairchild JK, Lohnberg JA and Bayley PJ (2016) Mindfulness as a Weight Loss Treatment for Veterans.

Front. Nutr. 3:30.

doi: 10.3389/fnut.2016.00030 mindfulness approach, mindfulness interventions for Veterans, a new pilot mindfulness-based weight loss program designed for Veterans, and future directions for this type of obesity treatment in Veterans. We conclude that this population may be uniquely poised to benefit from mindfulness-based treatments.

Keywords: veterans, veterans health, mindfulness, obesity, weight loss

\section{INTRODUCTION}

Mindfulness has been defined as a form of mental training that aims to foster "the awareness that emerges through paying attention on purpose, in the present moment, and non-judgmentally to the unfolding of experience moment by moment" [Ref. (1), p.145-146]. As implied by the broad definition, the term "mindfulness" has been used to describe a diverse range of practices that emphasize focused attention on present moment experience without judgment (1). Mindfulness can involve physical, mental, and emotional experiences (1-3). Research has shown that mindfulness is a skill that can be taught, acquired, and practiced (4). Although physical and mental health consequences are not emphasized in its use as a core Buddhist teaching, its practice is becoming increasingly popular, partly for its purported benefits for general health and psychological well-being.

In this perspective, we focus on mindfulness as a treatment for obesity in Veterans. As we will discuss below, a number of reviews have investigated mindfulness for various types of obesityrelated eating behaviors, and these studies have reported mindfulness to be of benefit in promoting weight loss among non-Veterans. We discuss this approach in the context of treating the Veteran population, since the Veterans Health Administration is the largest integrated healthcare provider in the U.S. consisting of more than 1,000 medical care sites and treating more than 8.3 million Veterans annually (5). Obesity in Veteran populations is at epidemic proportions; 78\% of Veterans are obese vs. $69 \%$ of the U.S. general population $(6,7)$. Over 10 years, Veterans with class III obesity cost the VA $\$ 8.9$ billion dollars more than normal weight Veterans, and these costs are projected to continue to soar in the future $(6,8)$. Moreover, the health effects of obesity can be even greater among Veterans, since obesity often co-occurs with other medical and psychological challenges associated with factors such as combat exposure, deployments, and unexpected relocations (9). 
The purpose of this paper is multipronged, as we will discuss what is known about treating obesity using a mindfulness approach, mindfulness studies for Veterans, and a new pilot weight loss program designed for Veterans using mindfulness techniques. Finally, we consider future issues regarding the use of mindfulness in treating obesity among Veterans.

Mindfulness-based treatments often guide participants to perform particular practices, such as mindful walking, meditation, or eating (see Table 1 for mindfulness definitions). Some clinicians and researchers, including the authors of this article, also expand the scope of mindfulness-based practices to include those practices that do not explicitly teach mindfulness exercises. Dubbed "acceptance and mindfulness procedures" by Hayes or "acceptance-based" practices by Forman and others, these treatments focus on the principle of "non-judgment" and

TABLE 1 | Description of common mindfulness techniques.

\begin{tabular}{|c|c|c|}
\hline \multicolumn{3}{|c|}{ Mindfulness techniques } \\
\hline Technique & Description & Example of instruction \\
\hline $\begin{array}{l}\text { Mindful } \\
\text { eating } \\
\text { exercise }\end{array}$ & $\begin{array}{l}\text { Eating with conscious } \\
\text { control over the } \\
\text { process of eating and } \\
\text { awareness and non- } \\
\text { judgment of sensory } \\
\text { stimuli }\end{array}$ & $\begin{array}{l}\text { Take a raisin in ... your hand ... imagin } \\
\text { that you have just dropped in from Mar } \\
\text { and have never seen an object like this } \\
\text { before ... now, prepare to chew the } \\
\text { raisin, noticing how and where it needs } \\
\text { to be for chewing }\end{array}$ \\
\hline $\begin{array}{l}\text { Mindful } \\
\text { walking } \\
\text { exercise }\end{array}$ & $\begin{array}{l}\text { Walking with conscious } \\
\text { control over the } \\
\text { process of walking } \\
\text { and awareness of } \\
\text { proprioceptive and } \\
\text { other stimuli without } \\
\text { judgment }\end{array}$ & $\begin{array}{l}\text { Bring the focus of your awareness to } \\
\text { the bottom of your feet, getting a direc } \\
\text { sense of the physical sensations of the } \\
\text { contact of the feet with the ground anc } \\
\text { of the weight of your body transmitted } \\
\text { through your legs and feet to the } \\
\text { ground }\end{array}$ \\
\hline $\begin{array}{l}\text { Mindful } \\
\text { breathing } \\
\text { exercise }\end{array}$ & $\begin{array}{l}\text { Breathing with } \\
\text { awareness of } \\
\text { the associated, } \\
\text { interoceptive sensations } \\
\text { and without judgment }\end{array}$ & $\begin{array}{l}\text { Notice expansion and contractions of } \\
\text { your lungs ... the subtle movements } \\
\text { in your chest and shoulders ... the air } \\
\text { passing through your nostrils }\end{array}$ \\
\hline
\end{tabular}

Body scan Paying attention to exercise interoceptive cues in successive parts of the body without judgment

Meditation Intentional focus on one's breath, a word, or other object, often with an emphasis on sustaining attention and then returning attention in the event of mind-wandering

Present- Concentration on what moment is happening in the focus present moment

Mindfulness Noticing the presence of thoughts of thoughts without judging them as good or bad and without any effort to change them

Notice what you are experiencing in the present moment, when you notice you are thinking about the future or past, return your attention to the present

Bring a gentle openness and interest to your [troublesome thought] with awareness and a non-judgmental attitude guide participants to incorporate intentional attention, present moment focus, and a non-judgmental attitude into their daily life without emphasizing mindfulness exercises [e.g., mindful walking or sitting; (10), p. 101; (11)]. Commonly practiced mindfulness-based and acceptance-based therapies include acceptance and commitment therapy [ACT; (12)], dialectical behavior therapy [DBT; (13)], and mindfulness-based cognitive therapy [MBCT; (14)].

General studies on the effectiveness of mindfulness for various indicators have reported positive results. General outcomes of mindfulness practice include self-control, objectivity, affect tolerance, enhanced flexibility, equanimity, improved concentration and mental clarity, emotional intelligence, and the ability to relate to others and one's self with kindness, acceptance, and compassion [for a review, see Ref. (3)]. A large comprehensive meta-analysis of 209 mindfulnessbased therapy studies reported moderate to large effects in pre- and post-studies and across other waitlist controlled studies, especially for reducing anxiety, depression, and stress (15).

Specific studies on the effectiveness of mindfulness-based interventions for disordered eating and weight loss have also reported positive results among non-Veteran samples. These interventions have been associated with improvements in emotional eating and binge eating behaviors $(16,17)$, as well as significant weight loss in 13 out of 19 studies in a recent review (18).

Although cognitive behavioral therapy (CBT) has been understood as the gold standard psychotherapeutic intervention in obesity treatment (19), these treatments produce relatively low adherence rates to diet and physical activity recommendations, and CBT participants lose far less weight than those in a controlled environment $(20,21)$. In addition, most participants regain most, if not all, of their weight within 5 years (22-24). There is emerging evidence that mindfulness interventions intervene at the points where CBT fails: making and/or maintaining recommended changes in dietary and physical activity (11).

Mindfulness-based skills could be useful in weight management for a number of reasons. Being aware of one's intake and expenditure of calories is critical to weight loss. Contrary to mindfulness, "mindless eating," which has been defined as "ways in which environmental factors trigger eating without conscious processing," has been associated with greater food consumption in a number of studies [(25), p. 17; (26-28)]. Thus, it has been suggested that self-regulation through monitoring one's diet and physical activity is essential for successful weight management.

Moreover, weight management is often associated with uncomfortable sensations and emotions (e.g., hunger, physical exertion, and sore muscles) that may be better tolerated and managed with mindfulness and acceptance-based techniques (11). As the authors of one review concluded, "individuals who exhibit greater mindfulness may be more resilient and better prepared to confront the challenges of weight management" (18).

\section{MINDFULNESS AND OBESITY IN VETERANS}

Among all studies on the use of mindfulness in Veterans, we identified only one published study that used mindfulness to treat disordered eating or obesity. This study reported that 
participation in mindfulness training alone did not influence eating behaviors; the intervention was associated with small increases in weight and body mass index at 4-month follow-up (29). However, the intervention enhanced mindfulness skills and reduced depressive symptoms over time, with medium to large effect sizes [Cohen's $d=0.69$ (95\% CI $=0.27-1.11)$ and 0.74 (95\% CI $=1.16-0.33)$, respectively]. Moreover, improvement in mindfulness skills was significantly and negatively correlated with changes in emotional and uncontrolled eating over time.

Apart from the results of this single study, the effectiveness of mindfulness treatments for obesity among Veterans or men in general is unknown. Mindfulness-based techniques have been associated with weight loss primarily in younger, female samples but have not been tested in the Veteran population, which is primarily older and males. As described in a review article of 14 studies on mindfulness and eating behavior or obesity, the majority of participants in these studies are women of age 40-60 years old, whereas most Veterans are men with a median age of 64 years old $(16,30)$. Moreover, nearly three-quarters of a sample of 45,477 overweight and obese Veterans report emotional eating behaviors and binge eating behavior for which men were at a particularly high risk (31). Mindfulness has also been useful in reducing symptoms for a number of common comorbid conditions in Veterans including post-traumatic stress disorder (PTSD), anxiety, and depression, as described below.

An attractive feature of these treatments is that, by teaching Veterans mindfulness-based skills for weight loss, one might improve various other mental health conditions as well. Conversely, there is some evidence that treatments, which lead to improvement in other mental health conditions, may facilitate better weight loss outcomes among those with mental health issues. For example, previous work has suggested an association between worse mental illness symptomatology and weight gain $(32,33)$. And, lifestyle interventions that improve weight loss also improve mental health symptoms $(34,35)$. These associations suggest that mindfulness-based interventions might be an effective treatment for common mental illnesses and obesity, among Veterans.

The mindfulness literature among Veteran samples has primarily focused on its usefulness in treating conditions such as depression and PTSD, common comorbidities among Veterans. Regarding mindfulness research focusing on Veterans, 38 articles on PubMed included (the string "veteran* and mindfulness") in the title and abstract of articles. Among these articles, the majority $(n=23)$ focused on PTSD. The effect of mindfulness on PTSD in Veterans has demonstrated promising results (36-40). For example, one review found positive effects on depression and PTSD in the majority of studies (41). As described earlier, a large meta-analysis of 209 mindfulness-based studies reported significant effects in reducing anxiety and depression (15). Depression, anxiety, and PTSD are also all conditions that are found more commonly in Veteran samples than in the general population $(42,43)$.

Taken together, preliminary results suggest that basic mindfulness training can be successful in reducing symptoms of depression, anxiety, and PTSD in Veterans, but additional evidence is required to address its effect on obesity. The only prior published study on disordered eating among Veterans (29) was limited by an intervention focused solely on mindfulness and stress reduction. We conjecture that, if this basic mindfulness training were combined with more specific instruction on nutrition, physical activity, and social behavior related to eating in Veterans, this more comprehensive intervention would be more effective in promoting weight loss and other healthy behaviors.

\section{MINDFULNESS INTERVENTION DESIGN}

The VA system addresses obesity among Veterans through the MOVE! program (44). The actual dissemination of the program varies across the country, but the minimal requirements of the MOVE! program include "screening all Veterans for ... obesityrelated conditions, referring Veterans for whom weight management is appropriate ..., conducting a multifactorial assessment, and providing support for weight self-management in ... individual or group care" [(45), p. 2]. The weight loss group component is a common feature across sites for which 16 weekly sessions are described online, but fewer sessions are typically implemented, due to group leader and participant time limitations. Among these sessions, only 13 min of group session time and one 2-page handout are allotted to discussing mindful eating. No other mindfulness materials appear in the MOVE! program.

Based on the potential of a more comprehensive intervention, we designed a pilot mindfulness-based weight loss group for Veterans. This pilot study was designed to determine the feasibility of recruiting Veterans for such an intervention and deliver a manualized mindfulness-based intervention. As such, this study does not include a control group and thus cannot speak to the efficacy of mindfulness compared to other, non-mindfulness interventions. We expected that Veterans would be motivated to join for the goal of weight loss, but we did not know how they might react to the mindfulness techniques. Our intervention was created by psychologists and trainees at the VA Palo Alto Health Care System and based on Brownell's book (46) entitled “LEARN Program for Weight Management 2000," which compiles years of psychological and behavioral research on weight loss and Williams' book (47) entitled, "The Mindful Way Through Depression: Freeing Yourself from Chronic Unhappiness," which combines cognitive therapy and mindfulness training as described by Kabat-Zinn (48); (a) into a type of therapy known as MBCT.

Similar to MBCT, our intervention was derived from both CBT and mindfulness-based stress reduction (MBSR), the group practice on which much of the mindfulness literature above is based $(49,50)$. Furthermore, our intervention included some elements of traditional CBT, such as "behavior chain analysis," which is a technique designed to help a person understand the function of a particular behavior by uncovering the many proximal and distal factors that led up to that behavior. The intervention excluded other elements of CBT such as "cognitive restructuring" (i.e., changing the content of a maladaptive thought) in favor of "mindfulness of thoughts" (see Table 1). The current intervention used imagery that better resembled the actual Veteran population and emphasized examples relevant to the Veterans' lives. It was 
built upon other services offered by VA and was envisioned as an auxiliary therapy, in this respect.

The current intervention was designed as an 8-week protocol for a group of 10-15 male and female Veterans. Each session included a lesson related to weight loss, followed by mindfulness instruction, and a mindfulness exercise. The subject matter of initial classes (see Table 2) included basic nutrition and physical activity education; however, the focus of this intervention was CBT and mindfulness techniques for making effective behavior changes. CBT elements included a chain analysis of problematic health behaviors and recognizing automatic negative thoughts that interfere with healthy living. Classes also focused on social interaction, intending to improve communication among friends, family, and people they encountered in eating-related situations.

The group leader taught both general and eating-specific mindfulness skills. For example, certain lessons focused on eating mindfully (i.e., as opposed to "eating mindlessly") or mindfully

TABLE 2 | Mindfulness weight loss intervention class schedule.

\section{Class schedule}

1. Week 1 - diet vs. lifestyle; recordkeeping; exercise

a. Diet = temporary; lifestyle $=$ life change

b. Recordkeeping is key

c. Every bit of physical activity is important

d. Mindful eating exercise

2. Week 2 - a balanced diet; high risk situations

a. Calculating and defining calories

b. Eating a balanced diet

c. Being mindful of behavior triggers

d. Mindful walking exercise

3. Week 3 - barriers to weight loss; emotions/stress

a. Discuss individual high risk situations

b. Describe role of emotions in eating

c. Stress reduction through "being present"

d. Without judging (i.e., mindfulness practice)

e. Focused breathing exercise

4. Week 4 - overcoming barriers, identify life values

a. Leading a value-guided life

b. Strategies for mindful eating

c. Tips for eating out

d. Body scan exercise

5. Week 5-Thoughts/feelings/behaviour, exercise

a. Connecting thoughts, emotions, behaviors

b. Effective coping strategies

c. Reasons for physical activity

d. Group-chosen mindfulness exercise

6. Week 6-social support; communication training

a. Recognizing automatic negative thoughts

b. Importance of social support

c. Mindfulness in daily life

d. Group-chosen mindfulness exercise

7. Week $7-$ Behavior chain analysis

a. Behavior chain analysis description

b. Creating your own behavior chain

c. Mindfulness/mindlessness and eating

d. Group-chosen mindfulness exercise

8. Week 8 - relapse prevention; review successes

a. Review of favorite skills

b. Review of mindfulness skills

c. Relapse vs. setback

d. Group-chosen mindfulness exercise keeping track of physical activity; mindfulness exercises taught at the end of each group typically focused on cultivating general mindfulness skills (e.g., mindful walking and mindful breathing) that incorporated focused attention on the present moment with a non-judgmental attitude. The final four classes reviewed a previously taught mindfulness skill selected by the group members. The group leader also referenced research describing the putative usefulness of mindfulness in improving abilities thought to be related to weight loss [e.g., concentration, self-control, emotion regulation, and decreasing stress; $(3,51)]$.

Once participants acquired specific mindfulness skills, the instructor regularly reminded group members how to apply these techniques throughout the week, particularly in the context of situations that might lead to disordered eating or less physical activity. This procedure contrasts with the only other study published on mindfulness and eating in Veterans, in which no explicit connection was drawn between improvement in mindfulness skills and improvement in eating behavior or other emotion or stress-related factors associated with losing weight.

In addition to mindfulness exercises, the course emphasized mindfulness concepts in-class. For example, the instructor described the concept of "acceptance" through class topics such as "Leading a Value-Driven Life," which emphasized the ability to tolerate discomfort or difficulty in certain parts of one's life on the path toward fulfilling a higher goal in line with one's values. In this way, an individual might need to tolerate the discomfort associated with passing by fast food restaurants in order to practice avoiding unhealthy food. This process would help him/ her fulfill his/her goal of weight loss and promote their value of good health. These concepts reflect core ACT concepts (12). In addition to $1.5 \mathrm{~h}$ of weekly in-class instruction, the intervention required participants to monitor their daily physical activity and diet and practice mindfulness exercises for $30 \mathrm{~min}$ daily at home.

\section{PILOT INTERVENTION FINDINGS}

The pilot intervention was implemented at the VA Palo Alto Health Care System (VA Palo Alto) in 2014. The VA Palo Alto is a Stanford University-affiliated teaching hospital that serves more than 85,000 enrolled Veterans and maintains one of the top three research programs in the VA system. The VA Palo Alto's Behavioral Medicine Clinic treats Veterans' medical problems using behavioral interventions and addresses coping with chronic illnesses. Sixteen Veterans were recruited from the VA Palo Alto's MOVE! Weight Loss Program. In total, 11 participants [mean age: 67 years; 10M/1F; mean baseline weight (lbs.): 249.5] completed at least 4 out of the 8 sessions. The institutional review board of Stanford University approved data collection.

Since this intervention was part of a clinical program and not a formal research study, care was taken to minimize participant burden. Therefore, few psychosocial outcome measures were administered. Measures included the Beck Depression Inventory-II (52), an updated version of the Questionnaire on Eating and Weight Patterns-Revised (53), and a novel four-item scale designed to assess participants' motivation and confidence in making weight-related behavioral changes. Weight was measured weekly at the beginning of every class using a digital scale. 
Over time, we observed decreases in average participant weight. Exploratory analyses revealed a trend toward reducing weight over time (mean $=1.76$ lbs. lost) among the 11 participants that completed at least 4 out of 8 total classes over the 8 -week program. The relationship between class attendance and weight loss was non-significant $(p>0.05)$. No other psychosocial outcome measures were significant.

Informal feedback suggested that participants enjoyed the program. One Veteran stated, “Thank you for the class. The group was very good. I enjoyed sitting and listening. It made learning better." Another Veteran noted, "I found joining with the group and attending the class very enjoyable and enlightening. You quickly relaxed in this very diverse group, and it brought us all together with ... respect and understanding of each other. One of the highlights that I take away from your class was that of 'mindfulness.' I've used [it] in my daily life and it's been extremely helpful in undertaking life's challenges." Other Veterans noted that they enjoyed learning about mindfulness, and how to practice these skills in their daily lives.

There were several limitations in this exploratory trial. Although participants seemed to enjoy the intervention and learn useful strategies for weight loss, only a trend toward weight loss was observed. Significant weight loss may require more time and practice. For example according to $\mathrm{MBSR}^{1}$ or MBCT materials ${ }^{2}$, programs typically consist of 8 weekly 2.5 -h sessions and one "all-day" weekend class. This current trial consisted of only 8 weekly 90 -minute sessions. Due to logistical limitations, no participant acceptability measures were administered. This intervention contained components known to be associated with weight loss (e.g., group interventions and elements of the LEARN protocol); therefore, it cannot be determined that mindfulness components specifically provided an added benefit. This trial was also limited by recruitment difficulties due to transportation difficulties, multiple medical appointments, and family commitments that limited their ability to complete the intervention. A more formal pilot trial with a non-mindfulness comparison group and a larger sample would provide more power and might test a greater number of hypotheses. A controlled comparison group is also needed in order to substantiate claims about the benefits of mindfulness compared to other, non-mindfulnessbased interventions.

\section{DISCUSSION}

This perspective and pilot study suggests that mindfulness-based interventions may be useful to Veterans who struggle with obesity, particularly those for whom other strategies have been unsuccessful or those resistant to other weight loss interventions. Certain mental illnesses are more common in Veterans, and these illnesses also seem to benefit from mindfulness interventions. Conversely, it is possible that the treatment of other mental illnesses might also be associated with increased weight loss. These data provide preliminary evidence to support a new approach to

${ }^{1} \mathrm{http}: / /$ www.umassmed.edu/cfm/stress-reduction/mbsr-8-week/ ${ }^{2}$ http://mbct.com/mbct-classes/ weight loss for Veterans. In this pilot, Veterans stated that they enjoyed the program, and satisfaction was evidenced by the large percentage $(83 \%)$ of Veterans who completed the intervention after attending at least two sessions.

\section{FUTURE DIRECTIONS}

A number of factors might moderate the effect of mindfulnessbased interventions on eating behaviors and obesity among Veterans. Based on findings from Forman et al. $(54,55)$, it is hypothesized that mindfulness skills that help manage emotions associated with food (e.g., tolerating discomfort around unhealthy foods without approaching them and uncomfortable social situations without triggering binges) will be instrumental to the success of future studies.

We continue to explore utilizing practical mindfulness exercises to strengthen skills (e.g., focused concentration, purposeful distraction, prioritizing, and following through with priorities) linked to weight loss. Like any skill, it is likely that more frequent practice of mindfulness exercises (e.g., particularly mindful eating) will provide larger effects on eating behavior and weight change. For example, repeated mindfulness practice is thought to improve executive function abilities associated with strengthened prefrontal lobe circuits (56) and might aid in making decisions regarding challenging food (i.e., avoiding unhealthy and approaching healthy food) and physical activity (i.e., avoiding sedentary and increasing exercise behavior) decisions (18). That said, in our study, we did not observe any relationship between weight loss and class attendance (e.g., "practice"). Thus, it remains to be determined whether this technique offers improved benefit to regular users who practice the technique frequently.

There is also some evidence for individual differences in response to mindfulness training, including differential responses due to temperament, personality, or genetic differences (57), suggesting that some individuals might benefit more from mindfulness practice than others. Finally, it is possible that similar results may have been observed with a non-mindfulness-based intervention; since we did not include a control intervention, we cannot determine whether the mindfulness components of our intervention were primarily responsible for the trends in weight loss or the satisfaction of group members. Future studies with a control condition are necessary to demonstrate the added benefit of mindfulness-based components.

Although not yet regularly used within the VA Health Care System, mindfulness-based interventions have the potential to contribute to various improved health behaviors including weight loss. Integrating these treatments into existing weight loss programs might be the most efficacious method of implementing this project system-wide.

\section{AUTHOR CONTRIBUTIONS}

Dr. MS is the primary author who wrote and edited much of the text. Dr. MS also conducted the pilot study in the publication and analyzed the data. Drs. JF and JL provided clinical supervision for Dr. MS throughout this project and edited this manuscript. Dr. JM spearheaded and designed the pilot group intervention 
and edited the manuscript. Dr. PB supervised the writing of the manuscript and wrote and edited the text.

\section{ACKNOWLEDGMENTS}

The authors wish to thank those veterans who participated in this study and all of the veterans and service members who have served in uniform. We also acknowledge Rachael Cho and

\section{REFERENCES}

1. Kabat-Zinn J. Mindfulness-based interventions in context: past, present, and future. Clin Psychol SciPract (2003) 10(2):144-56. doi:10.1093/clipsy.bpg016

2. Kabat-Zinn J. Full Catastrophe Living: Using the Wisdom of Your Body and Mind to Face Stress, Pain, and Illness. New York, NY: Delta Trade Paperbacks (2005).

3. Davis DM, Hayes JA. What are the benefits of mindfulness? A practice review of psychotherapy-related research. Psychotherapy (Chic) (2011) 48(2):198-208. doi:10.1037/a0022062

4. Baer RA, Smith GT, Hopkins J, Krietemeyer J, Toney L. Using self-report assessment methods to explore facets of mindfulness. Assessment (2006) 13(1):27-45. doi:10.1177/1073191105283504

5. U.S. Department of Veterans Affairs. Veterans Health Administration - About VHA [Online]. Washington, DC (2016). Available from: www.va.gov/health/ aboutVHA.asp

6. VA Management of Overweight and Obesity Working Group. VA/DoD Clinical Practice Guideline for Screening and Management of Overweight and Obesity. Washington, DC: VA Health Guidelines: US Veterans Affairs \& Department of Defense (2014)

7. Centers for Disease Control. Obesity and Overweight [Online]. Atlanta, GA: U.S. Department of Health \& Human Services. (2015). Available from: http:// www.cdc.gov/nchs/fastats/obesity-overweight.htm

8. Maciejewski ML, Neelon B, Yancy WS, Van Scoyoc L, McVay MA, Vijan S. Long-term healthcare costs of overweight and obese veterans. The Obesity Society Annual Meeting. Atlanta, GA (2013).

9. Tanofsky-Kraff M, Sbrocco T, Theim KR, Cohen LA, Mackey ER, Stice E, et al. Obesity and the US military family. Obesity (Silver Spring) (2013) 21(11):2205-20. doi:10.1002/oby.20566

10. Hayes SC. Acceptance, mindfulness, and science. Clin Psychol SciPract (2002) 9(1):101-6. doi:10.1093/clipsy.9.1.101

11. Forman EM, Butryn ML. A new look at the science of weight control: how acceptance and commitment strategies can address the challenge of selfregulation. Appetite (2015) 84:171-80. doi:10.1016/j.appet.2014.10.004

12. Hayes SC, Strosahl KD, Wilson KG. Acceptance and Commitment Therapy: The Process and Practice of Mindful Change. New York: Guilford Press (2012).

13. Linehan M. Cognitive-Behavioral Treatment of Borderline Personality Disorder. New York: Guilford Press (1993).

14. Segel ZV, Williams JMG, Teasdale JD. Mindfulness-Based Cognitive Therapy for Depression: A New Approach to Preventing Relapse. New York: Guilford Press (2002).

15. Khoury B, Lecomte T, Fortin G, Masse M, Therien P, Bouchard V, et al. Mindfulness-based therapy: a comprehensive meta-analysis. Clin Psychol Rev (2013) 33(6):763-71. doi:10.1016/j.cpr.2013.05.005

16. Katterman SN, Kleinman BM, Hood MM, Nackers LM, Corsica JA. Mindfulness meditation as an intervention for binge eating, emotional eating, and weight loss: a systematic review. Eat Behav (2014) 15(2):197-204. doi:10.1016/j.eatbeh.2014.01.005

17. O’Reilly GA, Cook L, Spruijt-Metz D, Black DS. Mindfulness-based interventions for obesity-related eating behaviours: a literature review. Obes Rev (2014) 15(6):453-61. doi:10.1111/obr.12156

18. Olson KL, Emery CF. Mindfulness and weight loss: a systematic review. Psychosom Med (2015) 77(1):59-67. doi:10.1097/PSY.0000000000000127

19. Jensen MD, Ryan DH, Apovian CM, Ard JD, Comuzzie AG, Donato KA, et al. 2013 AHA/ACC/TOS guideline for the management of overweight
R. Jay Schulz-Heik, Ph.D for their assistance with editing this manuscript.

\section{FUNDING}

This research was supported by U.S. Department of Veterans Affairs, Office of Public Health and the War Related Illness and Injury Study Centers (WRIISC).

and obesity in adults: a report of the American College of Cardiology/ American Heart Association Task Force on Practice Guidelines and The Obesity Society. Circulation (2014) 129(25 Suppl 2):S102-38. doi:10.1161/01. cir.0000437739.71477.ee

20. Heymsfield SB, Harp JB, Reitman ML, Beetsch JW, Schoeller DA, Erondu N, et al. Why do obese patients not lose more weight when treated with lowcalorie diets? A mechanistic perspective. Am J Clin Nutr (2007) 85(2):346-54.

21. Hall KD. Predicting metabolic adaptation, body weight change, and energy intake in humans. Am J Physiol Endocrinol Metab (2010) 298(3):E449-66. doi:10.1152/ajpendo.00559.2009

22. Wadden TA, Sternberg JA, Letizia KA, Stunkard AJ, Foster GD. Treatment of obesity by very low calorie diet, behavior therapy, and their combination: a five-year perspective. Int J Obes (1989) 13(Suppl 2):39-46.

23. Jeffery RW, Drewnowski A, Epstein LH, Stunkard AJ, Wilson GT, Wing RR, et al. Long-term maintenance of weight loss: current status. Health Psychol (2000) 19(1 Suppl):5-16. doi:10.1037/0278-6133.19.Suppl1.5

24. Wadden TA, Butryn ML. Behavioral treatment of obesity. Endocrinol Metab Clin North Am (2003) 32(4):981-1003, x. doi:10.1016/S0889-8529(03) 00072-0

25. Ogden J, Coop N, Cousins C, Crump R, Field L, Hughes S, et al. Distraction, the desire to eat and food intake. Towards an expanded model of mindless eating. Appetite (2013) 62:119-26. doi:10.1016/j.appet.2012.11.023S01956663(12)00475-8

26. Robinson E, Aveyard P, Daley A, Jolly K, Lewis A, Lycett D, et al. Eating attentively: a systematic review and meta-analysis of the effect of food intake memory and awareness on eating. Am J Clin Nutr (2013) 97(4):728-42. doi:10.3945/ajcn.112.045245ajcn.112.045245

27. Robinson E, Kersbergen I, Higgs S. Eating 'attentively' reduces later energy consumption in overweight and obese females. BrJ Nutr (2014) 112(4):657-61. doi:10.1017/S000711451400141XS000711451400141X

28. van de Veer E, van Herpen E, van Trijp HCM. Body and mind: mindfulness helps consumers to compensate for prior food intake by enhancing the responsiveness to physiological cues. J Consum Res (2016) 42(5):783-803. doi:10.1093/jcr/ucv058

29. Kearney DJ, Milton ML, Malte CA, McDermott KA, Martinez M, Simpson TL. Participation in mindfulness-based stress reduction is not associated with reductions in emotional eating or uncontrolled eating. Nutr Res (2012) 32(6):413-20. doi:10.1016/j.nutres.2012.05.008

30. U.S. Department of Veterans Affairs, National Center for Veterans Analysis and Statistics. Profile of Veterans: 2011 (2013). Avilable from: http://www. va.gov/vetdata/docs/SpecialReports/Profile_of_Veterans_2011.pdf

31. Higgins DM, Dorflinger L, MacGregor KL, Heapy AA, Goulet JL, Ruser C. Binge eating behavior among a national sample of overweight and obese veterans. Obesity (Silver Spring) (2013) 21(5):900-3. doi:10.1002/oby.20160

32. Hasler G, Lissek S, Ajdacic V, Milos G, Gamma A, Eich D, et al. Major depression predicts an increase in long-term body weight variability in young adults. Obes Res (2005) 13(11):1991-8. doi:10.1038/oby.2005.244

33. LeardMann CA, Woodall KA, Littman AJ, Jacobson IG, Boyko EJ, Smith $B$, et al. Post-traumatic stress disorder predicts future weight change in the Millennium Cohort Study. Obesity (Silver Spring) (2015) 23(4):886-92. doi:10.1002/oby.21025

34. Danielsen KK, Sundgot-Borgen J, Maehlum S, Svendsen M. Beyond weight reduction: improvements in quality of life after an intensive lifestyle intervention in subjects with severe obesity. Ann Med (2014) 46(5):273-82. doi:10.31 09/07853890.2013.874660 
35. Rubin RR, Wadden TA, Bahnson JL, Blackburn GL, Brancati FL, Bray GA, et al. Impact of intensive lifestyle intervention on depression and healthrelated quality of life in type 2 diabetes: the Look AHEAD Trial. Diabetes Care (2014) 37(6):1544-53. doi:10.2337/dc13-1928dc13-1928

36. Price CJ, McBride B, Hyerle L, Kivlahan DR. Mindful awareness in bodyoriented therapy for female veterans with post-traumatic stress disorder taking prescription analgesics for chronic pain: a feasibility study. Altern Ther Health Med (2007) 13(6):32-40.

37. Nakamura Y, Lipschitz DL, Landward R, Kuhn R, West G. Two sessions of sleep-focused mind-body bridging improve self-reported symptoms of sleep and PTSD in veterans: a pilot randomized controlled trial. J Psychosom Res (2011) 70(4):335-45. doi:10.1016/j.jpsychores.2010.09.007

38. Branstrom R, Kvillemo P, Moskowitz JT. A randomized study of the effects of mindfulness training on psychological well-being and symptoms of stress in patients treated for cancer at 6-month follow-up. Int J Behav Med (2012) 19(4):535-42. doi:10.1007/s12529-011-9192-3

39. Kearney DJ, McDermott K, Malte C, Martinez M, Simpson TL. Effects of participation in a mindfulness program for veterans with posttraumatic stress disorder: a randomized controlled pilot study. J Clin Psychol (2013) 69(1):14-27. doi:10.1002/jclp.21911

40. Kim SH, Schneider SM, Bevans M, Kravitz L, Mermier C, Qualls C, et al. PTSD symptom reduction with mindfulness-based stretching and deep breathing exercise: randomized controlled clinical trial of efficacy. J Clin Endocrinol Metab (2013) 98(7):2984-92. doi:10.1210/jc.2012-3742

41. Kim SH, Schneider SM, Kravitz L, Mermier C, Burge MR. Mind-body practices for posttraumatic stress disorder. J Investig Med (2013) 61(5):827-34. doi:10.231/JIM.0b013e3182906862

42. Hoge CW, Auchterlonie JL, Milliken CS. Mental health problems, use of mental health services, and attrition from military service after returning from deployment to Iraq or Afghanistan. JAMA (2006) 295(9):1023-32. doi:10.1001/jama.295.9.1023

43. Ikin JF, Sim MR, McKenzie DP, Horsley KW, Wilson EJ, Moore MR, et al. Anxiety, post-traumatic stress disorder and depression in Korean War veterans 50 years after the war. Br J Psychiatry (2007) 190:475-83. doi:10.1192/ bjp.bp.106.025684

44. U.S. Department of Veterans Affairs. MOVE! Weight Management Program [Online]. Washington, DC (2015). Available from: http://www.move.va.gov/

45. U.S. Department of Veterans Affairs. MOVE! Weight Management Program For Veterans (MOVE!) VHA Handbook 1120.1. Washington, DC: US Department of Veterans Affairs (2011). Available from: http://www1.va.gov/ vhapublications/ViewPublication.asp?pub_ID=2403

46. Brownell KD, Center LE. The LEARN Program for Weight Management 2000: Lifestyle, Exercise, Attitudes, Relationships, Nutrition. Dallas, TX: American Health Pub. Co.: LEARN Education Center Distributor (2000).
47. Williams JMG. The Mindful Way through Depression: Freeing Yourself from Chronic Unhappiness. New York: Guilford Press (2007).

48. Kabat-Zinn J. Wherever You Go, There You Are: Mindfulness Meditation in Everyday Life. New York: Hyperion (2005).

49. Zettle RD. ACT for Depression: A Clinician's Guide to Using Acceptance \& Commitment Therapy in Treating Depression. Oakland, CA: New Harbinger Publications (2007).

50. Kuyken W, Byford S, Taylor RS, Watkins E, Holden E, White K, et al. Mindfulness-based cognitive therapy to prevent relapse in recurrent depression. J Consult Clin Psychol (2008) 76(6):966-78. doi:10.1037/a0013786200816943-016

51. Khoury B, Sharma M, Rush SE, Fournier C. Mindfulness-based stress reduction for healthy individuals: a meta-analysis. J Psychosom Res (2015) 78(6):519-28. doi:10.1016/j.jpsychores.2015.03.009S0022-3999(15) 00080-X

52. Beck AT, Steer RA, Brown GK. Manual for the Beck Depression Inventory-II. San Antonio, TX: Psychological Corporation (1996).

53. Spitzer RL, Yanovski S, Wadden T, Wing R, Marcus MD, Stunkard A, et al. Binge eating disorder: its further validation in a multisite study. Int J Eat Disord (1993) 13(2):137-53.

54. Forman EM, Butryn ML, Juarascio AS, Bradley LE, Lowe MR, Herbert JD, et al. The mind your health project: a randomized controlled trial of an innovative behavioral treatment for obesity. Obesity (Silver Spring) (2013) 21(6):1119-26. doi:10.1002/oby.20169

55. Forman EM, Butryn ML, Manasse SM, Bradley LE. Acceptance-based behavioral treatment for weight control: a review and future directions. Curr Opin Psychol (2015) 2:87-90. doi:10.1016/j.copsyc.2014.12.020

56. Gard T, Holzel BK, Lazar SW. The potential effects of meditation on age-related cognitive decline: a systematic review. Ann N Y Acad Sci (2014) 1307:89-103. doi:10.1111/nyas. 12348

57. Tang YY, Holzel BK, Posner MI. The neuroscience of mindfulness meditation. Nat Rev Neurosci (2015) 16(4):213-25. doi:10.1038/nrn3916

Conflict of Interest Statement: The authors declare that the research was conducted in the absence of any commercial or financial relationships that could be construed as a potential conflict of interest.

Copyright (c) 2016 Stanton, Matsuura, Fairchild, Lohnberg and Bayley. This is an open-access article distributed under the terms of the Creative Commons Attribution License (CC BY). The use, distribution or reproduction in other forums is permitted, provided the original author(s) or licensor are credited and that the original publication in this journal is cited, in accordance with accepted academic practice. No use, distribution or reproduction is permitted which does not comply with these terms. 